\title{
Heterogeneity and effectiveness analysis of COVID- 19 prevention and control in major cities in China through time-varying reproduction numbers estimation
}

\section{Qing Cheng ( $\sim$ sgggps@163.com )}

College of Systems Engineering and Science and Technology on Information Systems Engineering Laboratory, National University of Defense Technology

\section{Zeyi Liu}

College of Systems Engineering and Science and Technology on Information Systems Engineering Laboratory, National University of Defense Technology

\section{Guangquan Cheng}

College of Systems Engineering and Science and Technology on Information Systems Engineering Laboratory, National University of Defense Technology

\section{Jincai Huang}

College of Systems Engineering and Science and Technology on Information Systems Engineering Laboratory, National University of Defense Technology

\section{Research Article}

Keywords: COVID-19, effectiveness of prevention and control measures, estimate time-varying reproduction numbers method, serial correlation method

Posted Date: April 2nd, 2020

DOl: https://doi.org/10.21203/rs.3.rs-20987/v1

License: (1) This work is licensed under a Creative Commons Attribution 4.0 International License. Read Full License

Version of Record: A version of this preprint was published on December 15th, 2020. See the published version at https://doi.org/10.1038/s41598-020-79063-x. 


\title{
Heterogeneity and effectiveness analysis of COVID-19 prevention and control in major cities in China through time-varying reproduction numbers estimation
}

\author{
Qing Cheng ${ }^{1,2^{*}}$, Zeyi Liu ${ }^{1,2}$, Guangquan Cheng ${ }^{1,2}$, Jincai Huang ${ }^{1,2}$ \\ ${ }^{1}$ College of Systems Engineering, \\ National University of Defense Technology, \\ Changsha 410073, People's Republic of China \\ *email:sgggps@163.com \\ ${ }^{2}$ Science and Technology on Information Systems Engineering Laboratory, \\ National University of Defense Technology, \\ Changsha 410073, People's Republic of China
}

\begin{abstract}
From December 31, 2019, a large-scale 2019 novel coronavirus disease (COVID-19) broke out in China. Tracking and analyzing the heterogeneity and effectiveness of cities' prevention and control for COVID-19 epidemic is essential to design and adjust epidemic prevention and control. The number of newly infected cases in 25 China's worst cities for COVID-19 epidemic from January 11 to February 10 was collected. The heterogeneity and effectiveness of these 25 cities' prevention and control measures for COVID-19 were analyzed by using a estimate time-varying reproduction numbers method and a serial correlation method. The results shown that the effective reproduction number $(\mathrm{R})$ in 25 cities showed a downward trend as a whole, but there was a significant difference in the $\mathrm{R}$ change trends among cities indicating that there was heterogeneity in the spread and control of COVID-19 in cities. Moreover, the COVID-19 control in 21 of 25 cities were effective and the risk of infection was decreasing due to their $\mathrm{R}$ had dropped below 1 on February 10, 2020 and the average decline of $\mathrm{R}$ in the past 5 days was greater than 0, while cities of Wuhan, Tianmen, Ezhou and Enshi were still difficult to effectively control the COVID-19 epidemic in a short period of time because their $\mathrm{R}$ was also greater than 1 .
\end{abstract}

\section{Introduction}

On December 31, 2019, the Chinese city of Wuhan has reported the confirmed case of the 2019 novel coronavirus disease (COVID-19), and other cities in China have also confirmed the case of COVID-19. Consequently the COVID-19 has even been spreading to other countries, such as the United States, Japan, and Thailand[1], which may trigger the global outbreak of COVID-19. The WHO has listed the COVID-19 epidemic as the Public Health Emergency of International Concern (PHEIC) on January 31, 2020. The number of people infected with COVID-19 continue to rise. Most Chinese provinces have initiated first-level public health emergency response in response to COVID-19 outbreak. For example, Guangdong, Hunan, and Zhejiang provinces initiated the firstlevel public health emergency response on January 23, 2020, Hubei, Tianjin, Beijing, Shanghai, Chongqing, Jiangxi, Sichuan, Yunnan, and other provinces also launched first-level public health emergencies responses on January 24. These provinces have taken measures to isolate suspected cases, sterilize public areas, and restrict traffic to limit the COVID-19 epidemic. Wuhan where the COVID-19 epidemic was most severe, even began closing the city on January 23, 2020. In order to 
control the COVID-19 epidemic, Wuhan's urban bus, subway, ferry, and long-distance passenger services have been suspended.

So, How effective are cities in controlling COVID-19 epidemic? The effective reproduction number $\mathrm{R}$ is the expected number of secondary cases generated by an infectious case once an epidemic is underway [2]. $\mathrm{R}$ is able to measure the effectiveness of control of COVID-19 epidemic. Although there are many research on estimation the $\mathrm{R}$ of early propagation of COVID-19 [3-5], for example the key epidemiologic time-delay distributions and the basic reproductive number were estimated based on the first 425 patients with confirmed COVID-19 infected pneumonia[3], and [4] estimated the basic reproduction number of the infection to be significantly greater than one and predicted the COVID-19 epidemic based on the SEIR model. However, the R estimation of COVID-19 epidemic in these studies is a static value, the $\mathrm{R}$ changes dynamically with the prevention and control of COVID-19 epidemic. Therefore, the static R estimation cannot describe the current effectiveness of prevention and control of COVID-19 epidemic, Moreover, the previous research focused on the $\mathrm{R}$ estimation of the overall transmission of COVID-19. In fact, since the various social environments, differences in control measures, and the number of imported cases in different cities, the spread control of COVID-19 may not be the same across cities. Thus, this paper aims to answer the following questions: how effective are the control measures taken by the cities in controlling COVID-19 epidemic? When will COVID-19 prevention and control measures begin to play an important role in different cities? Whether the effectiveness of control of COVID-19 epidemic is the same across cities? 37,726 people have been confirmed to be infected with COVID-19 in China by February 10, while the confirmed cases in 25 of the most severely hit cities account for $92 \%$ of the total number. Therefore, based on the number of infected cases in the top 25 severe cities from January 11, 2020 to February 10, 2020, a dynamic estimation method of R [6] was used to estimate the $\mathrm{R}$ changes of 25 cities to assess the degree of control of COVID-19 epidemic and a serial correlation method [6] was used to analyze the differences in the control effect of COVID-19 epidemic among cities. Meanwhile, critical time points for COVID-19 outbreak control in various cities were found by analyzing the starting time of $\mathrm{R}<1$. This study helps to address the effects of COVID-19 control measures in different cities and the differences between cities.It is conducive to improve epidemic prevention measures and providing a reference for epidemic control and prediction of inflection control points. It also provides guidance for the government to adjust prevention and control measures to COVID-19 epidemic.

\section{Results}

By February 10, 2020, the number of infected cases in 25 cities $(34,737)$ accounted for $92 \%$ of the total number of infected cases in China $(37,726)$. The locations of 25 cities and the number of infected for COVID-19 are shown in Figure 1. Most of the serious cities are concentrated in Hubei Province. The worst cities are Wuhan (18455 infected cases, by February 10), other cities with cumulative infections exceeding 1,000 include Xiaogan (2620), Huanggang(2284), Suizhou(1095), Xiangyang(1089) Jingzhou(1075). This is because the source of the outbreak in Wuhan is quickly spread to the surrounding cities. Large cities outside Hubei province with close transport links to Wuhan could also become outbreak epicentres [1], such as Wenzhou (474), Chongqing (476), Shenzhen (357), Beijing (345), Guangzhou (317), Xinyang(227), Shanghai (302), Changsha (219), 


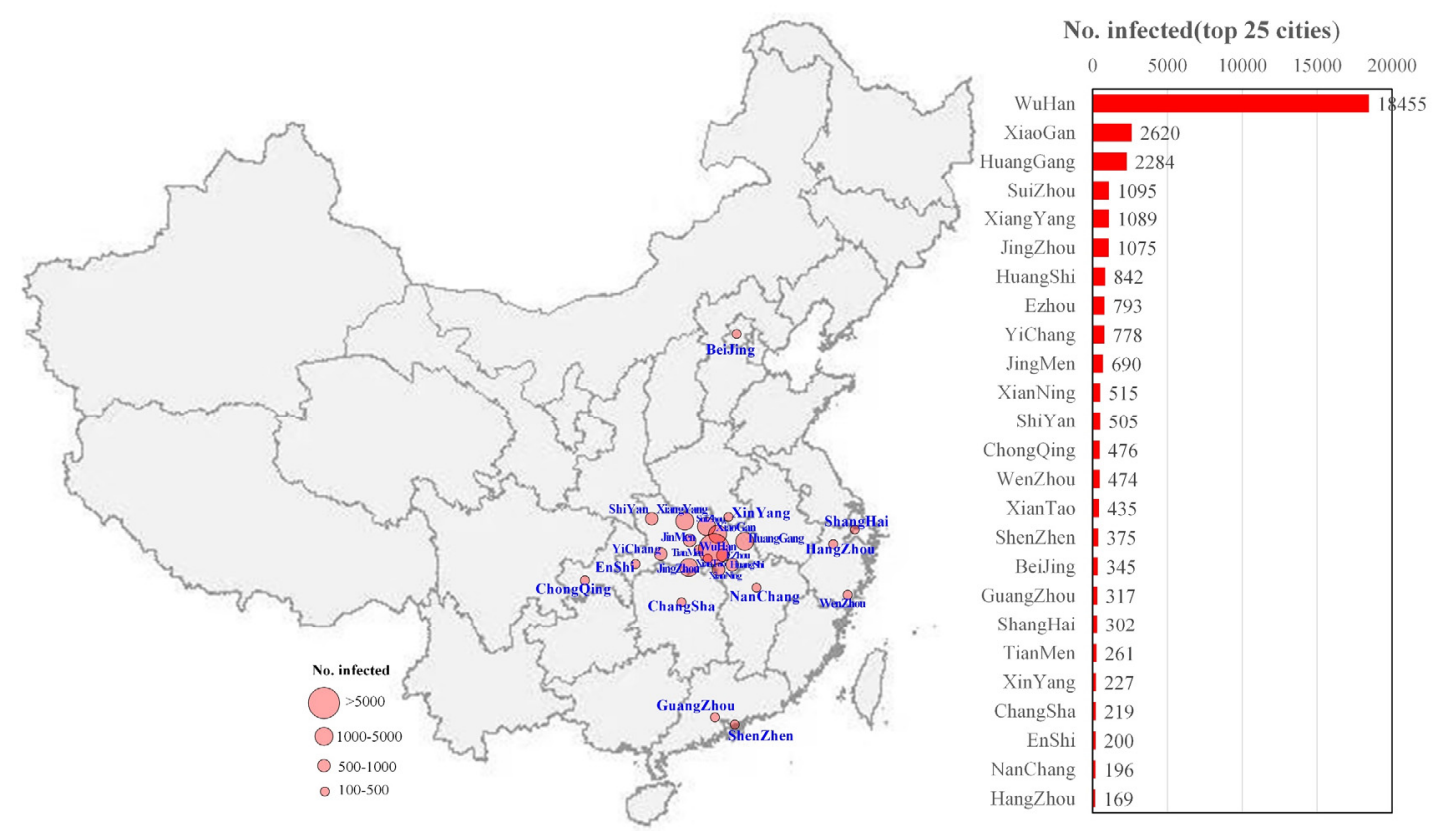

Figure 1: Spatial distribution of 25 China's worst cities for COVID-19 epidemic.

The $\mathrm{R}$ value of 25 cities is estimated per day to analyze whether the effectiveness of COVID-19 control among cities is the same (shown in Figure 2). Obviously, all cities' $R$ value show a downward trend as a whole, but there are differences in the $\mathrm{R}$ change trends among cities. For example, the $\mathrm{R}$ values of Huanggang, Suizhou, Xiangyang, Jinzhou, Huangshi, and other cities decline steadily, while Ezhou, Enshi, and Tianmen started to rise after a period of decline. To analyze the heterogeneity of the downward trend in R values among cities, a serial correlation method [7] was used to calculate the correlation of the $\mathrm{R}$ time series among cities.

The correlation coefficient of the R time series among cities is shown in Figure 3, and Figure 4 shows the p-values for testing the hypothesis of no correlation. From the black box in Figure 4, it can be seen that except for Ezhou, Tianmen, Xiaogan, and Wuhan, the correlation of the R time series among other cities is significant. This shows that although they are located in different places, the effectiveness of COVID-19 control is similar. Besides, after a period of decline, the R values of Ezhou, Tianmen, and XiaoGan have been slowly increasing. 


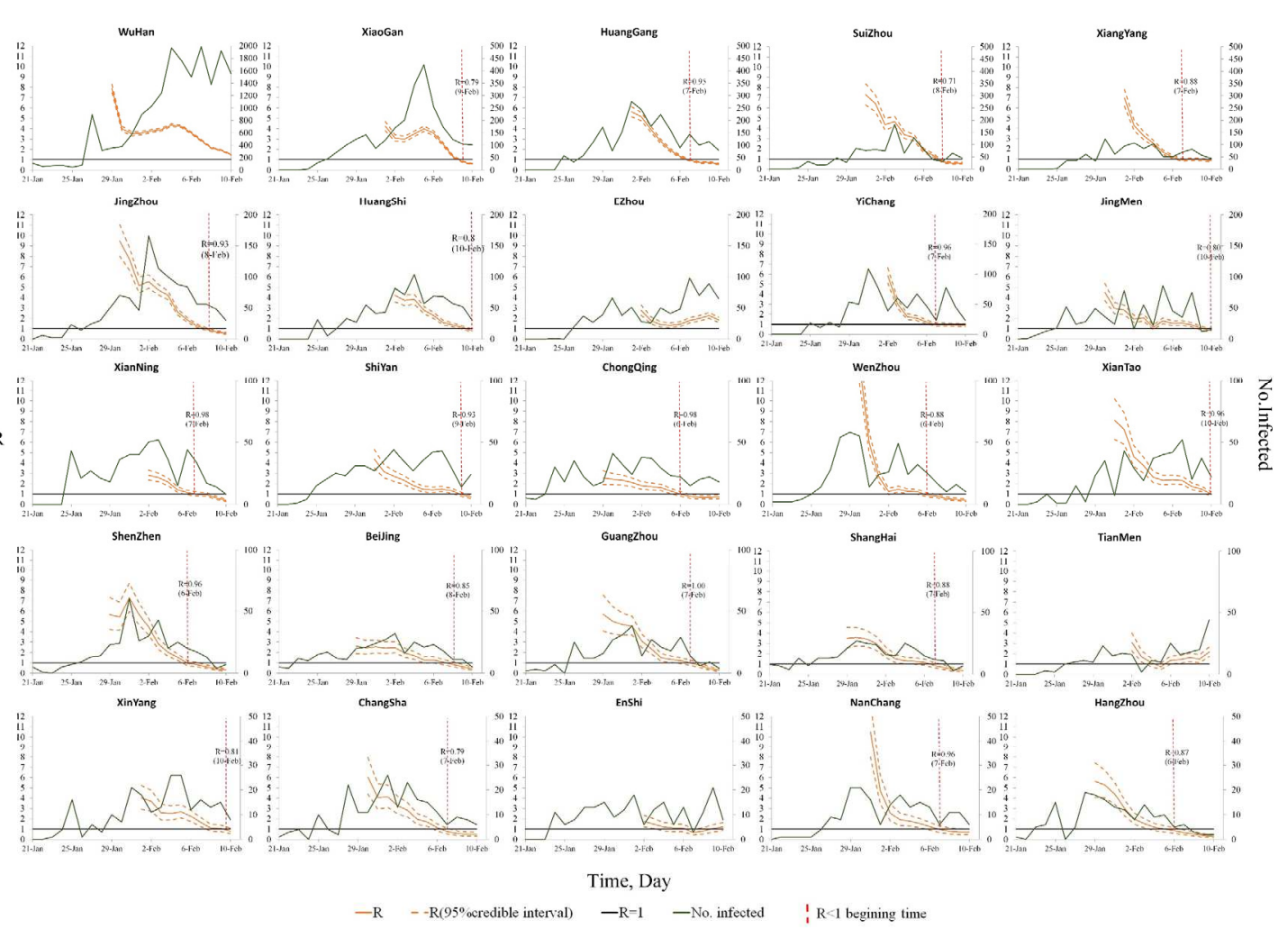

Figure 2: $\mathrm{R}$ change trends of 25 China's worst cities for COVID-19 epidemic.

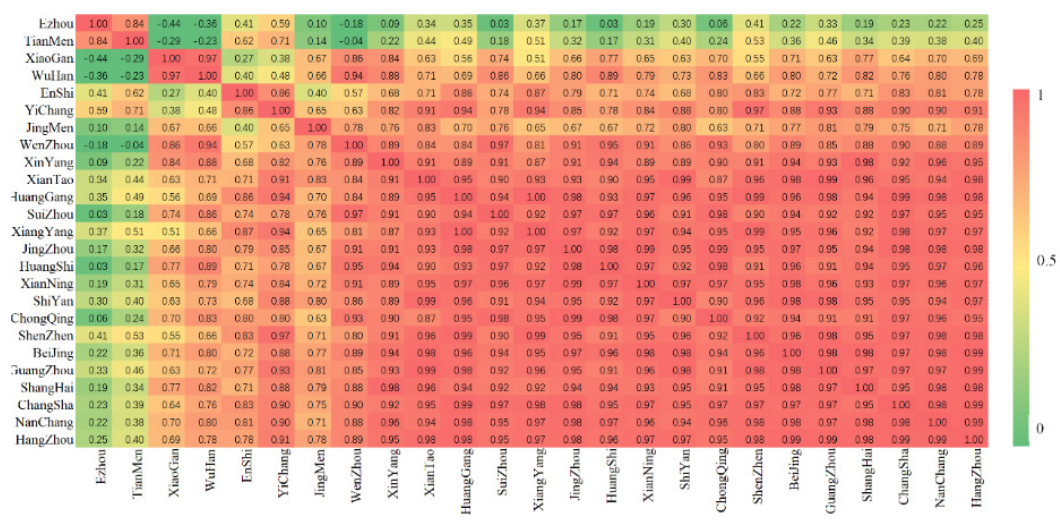

Figure 3: The correlation coefficient of $\mathrm{R}$ time series among cities.

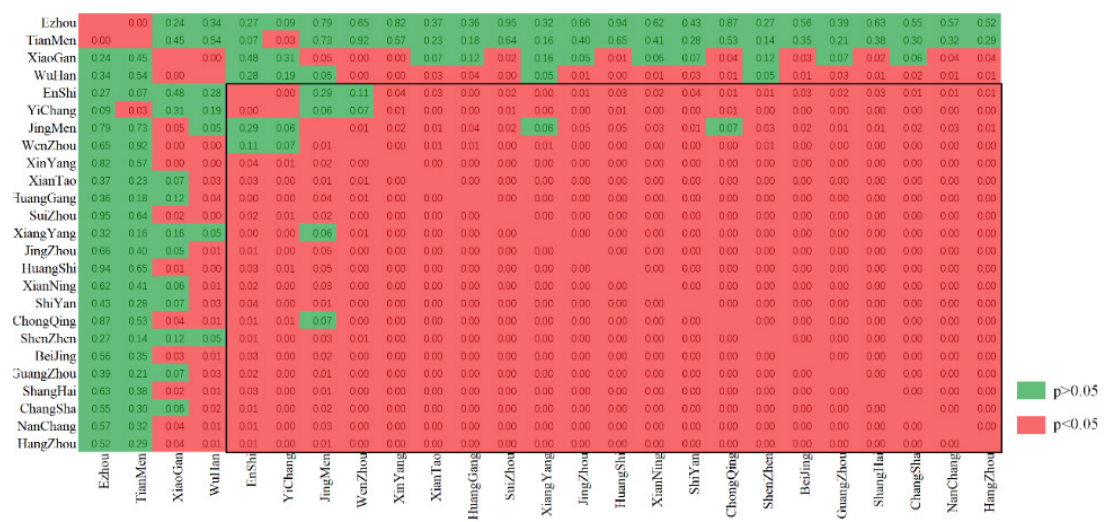

Figure 4: The $p$ value of correlation coefficient of $R$ time series among cities (if the $p<0.05$, the correlation is significant). 
Although most cities have strong correlations in $\mathrm{R}$ change tends, their $\mathrm{R}$ values are different. The relationship between the $\mathrm{R}$ value of each city on February 10, 2020 (denoted as the $\mathrm{R}_{\mathrm{t}}$ ) and the average decline in its $\mathrm{R}$ in the last 5 days (denoted as the $\Delta \mathrm{R}$ ) was used to find some patterns, the result shown in Figure 5 (circle size measures the total number of infected case). And the $R_{t}=1$ and $\Delta \mathrm{R}=0$ are used to divide Figure 5. The $\mathrm{R}_{\mathrm{t}}$ value of the city in the lower right quadrant of Figure 5 has been lower than 1 on February 10, and their $\Delta \mathrm{R}>0$, indicating that the COVID-19 in these cities has been effectively controlled, such as Xiantao, Yichang, Xinyang, Xiangyang, Jingmen, Huangshi, Nanchang, Chongqing, Shiyan, Huanggang,Xiaogan, ShenZhen, GuangZhou. It is worth noting that all cities outside Hubei belong to them. The cities in the upper left quadrant of Figure 5 not only the $\mathrm{R}_{\mathrm{t}}$ value is greater than 1 but also $\Delta \mathrm{R}>0$, such as Tianmen $\left(\mathrm{R}_{\mathrm{t}}=2.17,95 \% \mathrm{CI}: 1.73-2.67, \Delta \mathrm{R}=-\right.$ $0.20)$, Ezhou $\left(\mathrm{R}_{\mathrm{t}}=1.85,95 \% \mathrm{CI}: 1.62-2.10, \Delta \mathrm{R}=-0.11\right)$, and EnShi $\left(\mathrm{R}_{\mathrm{t}}=1.22,95 \% \mathrm{CI}: 0.88-1.62\right.$,

$\Delta \mathrm{R}=-0.04$. This shown that these cities not only have a serious COVID-19 epidemic but also have a tendency to continue to deteriorate. As shown in the upper right corner of Figure 4, Wuhan $\left(\mathrm{R}_{\mathrm{t}}=1.50,95 \% \mathrm{CI}: 1.46-1.54, \Delta \mathrm{R}=0.52\right)$ had a large $\mathrm{R}$ value on February 10 although it is consistent with the $\mathrm{R}$ trend of most cities. Thus, Wuhan has not yet carried out stable control of COVID-19 epidemic, but it is optimistic that its $\Delta \mathrm{R}>0$.

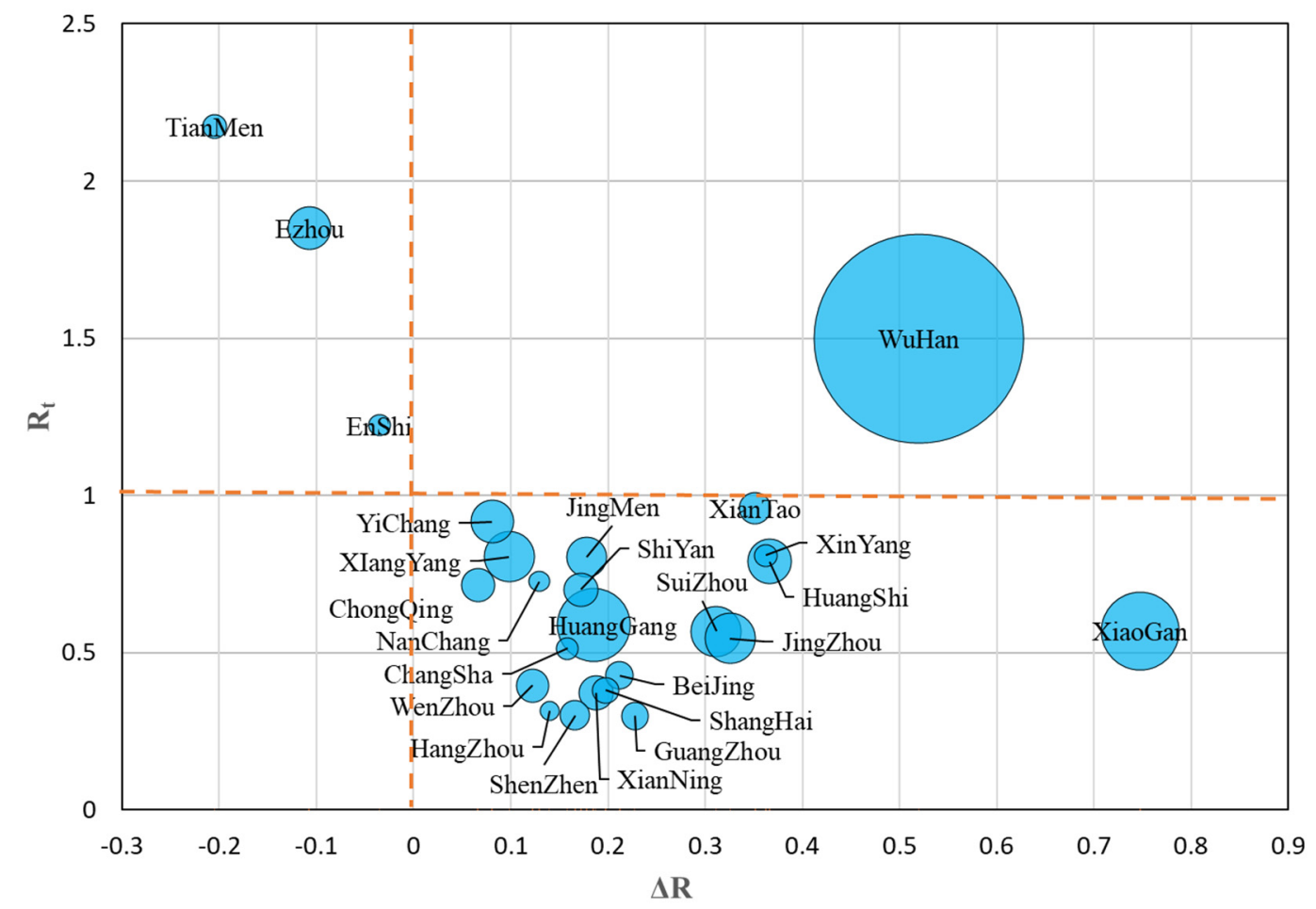

Figure 5: The relationship between the $\mathrm{R}$ value on February 10, $2020\left(\mathrm{R}_{\mathrm{t}}\right)$ and the average decline of $R$ in the past five days $(\Delta R)$, where the size of the circle represents the number of infected in each city.

The $\mathrm{R}$ drops to 1 indicating that the control measures have effectively controlled the epidemic [8]. The starting time of $\mathrm{R}<1$ was considered as the "turning point" for COVID-19 control in our studies. It is obvious from Figure 6 that the starting time of $R<1$ is not the same in various cities. By combining the time for each city to initiate a first-level public health emergency response, how long 
it takes to keep R below 1 and that $\mathrm{R}$ continues to decline is shown in Figure 6. Except for Wuhan, Ezhou, Suizhou, and Tianmen, the cities need an average of 14.9 day (95\%CI: 14.4- 15.5 day) from the first-level public health emergency response initiated to $\mathrm{R}<1$ without a significant increase. Thus, the "turning point" of COVID-19 control in most cities is thought to have occurred around February 7.

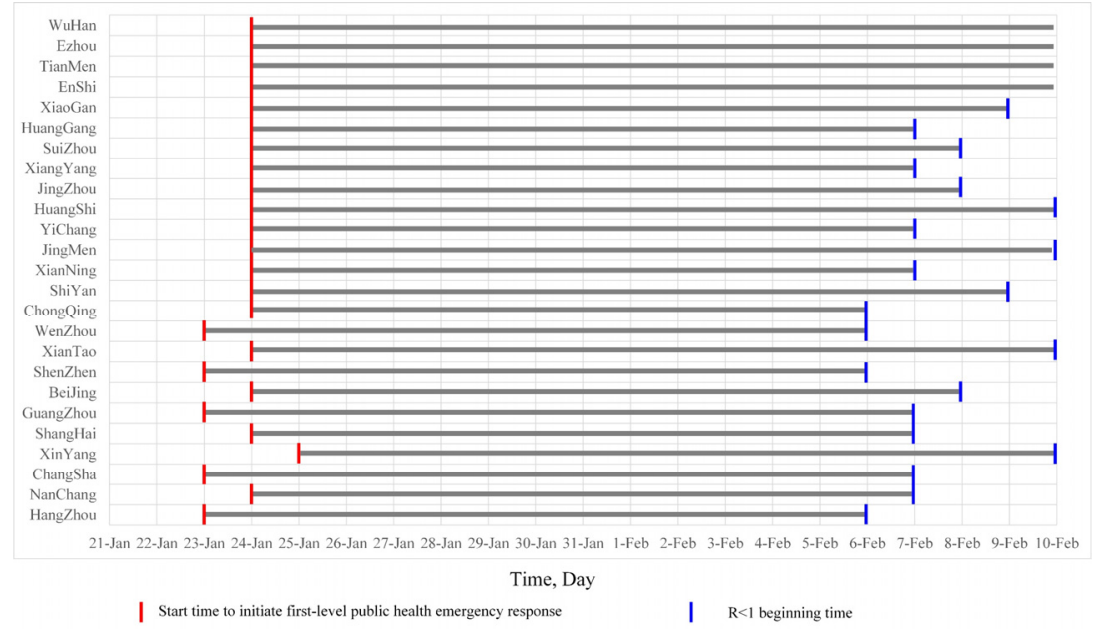

Figure 6: The time for each city to initiate a first-level public health emergency response and the start time for $\mathrm{R}<1$.

\section{Discussion}

The calculation and tracking of the R value can effectively handle the COVID-19 epidemic, and judge the effect of the current prevention and control measures. In order to better implement or modify the COVID-19 prevention and control measures, it is necessary to consider the instantaneous change of R, especially to find a downward trend in R time series. And it is possible to analyze the spatial heterogeneity of the COVID-19 transmission by estimating the difference in the change of $\mathrm{R}$ among cities. In this paper, 25 China's worst cities for COVID-19 epidemic are selected for R's tracking and calculations.

All cities' $R$ show a downward trend as a whole (Figure 2) which suggesting that the prevention and control measures in these cities have played an effective role. However, there is a difference in the $\mathrm{R}$ change trend among cities indicating heterogeneity in the spread and control of COVID-19 in various cities. Moreover, a major pattern in the $\mathrm{R}$ change trend of these cities was found through correlation analysis. Enshi, Yichang, Jingmen, Wenzhou, Xinyang, Xiantao, Huanggang, Suizhou, Xiangyang, Jingzhou, Huangshi, Xianning, Shiyan, Chongqing, Shenzhen, Beijing, Guangzhou, Shanghai, Changsha, Nanchang, and Hangzhou belong to this pattern and their $\mathrm{R}$ change trends are very similar. The characteristic of this pattern is that the $\mathrm{R}$ continues to decline steadily, which shows that although the severity of COVID-19 epidemic in these cities is different, their prevention and control measures have almost the similar effect. Further analysis of the $\mathrm{R}$ value of these cities on February 10, 2020 and the average decline of $\mathrm{R}$ in the past 5 days. The $\mathrm{R}$ of these cities (except Enshi) have all dropped below 1 and $\Delta \mathrm{R}$ is greater than 0 (the lower right quadrant in Figure 5), indicating that these cities' prevention and control measures are effective and the risk of infection is decreasing. However, the R of Ezhou, Tianmen, and Enshi are still greater than 1 on February 10, 
2020 and the 5-day average decline of $\mathrm{R}$ is less than 0 . It can be considered that these cities are still difficult to effectively control the high-risk of COVID-19 in a short period of time, and their R has fallen for some time and then increased again, the government must continue to strengthen epidemic prevention measures and cannot relax in these cities. It is also worth noting that Wuhan's $\mathrm{R}$ is greater than 1, but it is more optimistic that its 5-day average decline is larger.

By comparing the time when each city starts the first-level public health emergency response and the time when R starts to be less than 1. We found that except for WuHan, Ezhou, Enshi and XiaoGan, it took about two weeks for other cities to start the first-level public health emergency response to effectively control the COVID-19 epidemic. In other words, the "turning point" of COVID-19 control in these cities was considered to occur around February 7.

The time for $\mathrm{R}$ to start calculation in our model must fulfill three criteria[6]: the $\mathrm{R}$ must be calculated after a time window ( $>3$ ). According to the above discussion in function 2, at least 11 cases have been observed (the time denoted as $t_{\mathrm{c}}$ )since the beginning of the epidemic based on posterior coefficient of variation must be less than a threshold $\mathrm{CV}=0.3$, and the estimation of $\mathrm{R}$ depends on the probability distribution of the serial interval, that is, it is difficult to observe the complete data to estimate $\mathrm{R}$ in a serial interval, thus an accurate estimation of $\mathrm{R}$ must be performed after a serial interval (the average serial interval in this article is 7.5). So I took the maximum of $\tau, t_{\mathrm{c}}$ and serial interval as the starting time of $\mathrm{R}$ calculation. Moreover, a smaller time window $\tau$ will result in faster detection of COVID-19 transmission changes, larger $\tau$ will result in smoother. In order to test the sensitivity of the time window to R estimation, we selected $\tau=2,3,4,5,6,7$, and analyzed the $\mathrm{R}$ estimation in each city. The result is shown in Figure 7. It can be seen that the $\mathrm{R}$ values are slightly different based on different time windows, thus the selection of different time windows may have an impact on the time when $\mathrm{R}$ is first less than 1, However, the changing trend of $\mathrm{R}$ will not change, so it will not affect the results of our analysis of the effect of prevention and control of COVID-19 in various cities. In order to enable faster detection of COVID-19 transmission changes, the minimum reasonable time window ( $\tau=3$ ) is chosen in the studies.

Identifying and tracking changes in $\mathrm{R}$ is a way to effectively handle the changes in the epidemic situation in various cities and assist in the guidance of epidemic prevention and control. However, it does not mean that the future $\mathrm{R}$ trend of each city will change according to the current development trend. For example, some imported case from Wuhan may not show symptoms of infection but maybe in an incubation period but they conceal their contact history and fail to take effective isolation, which may make prevention and control measures invalid and infect more people, because it has been proven that COVID-19 can also be infected during the incubation period[9]. Therefore, it is necessary to continuously track the number of infected per day and implement an update to calculate the $\mathrm{R}$ value. Above all, from the situation of epidemic prevention and control, each city should track the $\mathrm{R}$ and its changing trend. Now, no city can relax the epidemic prevention and control. Some cities have a high R, and they should strengthen their prevention and control for COVID-19 epidemic. 

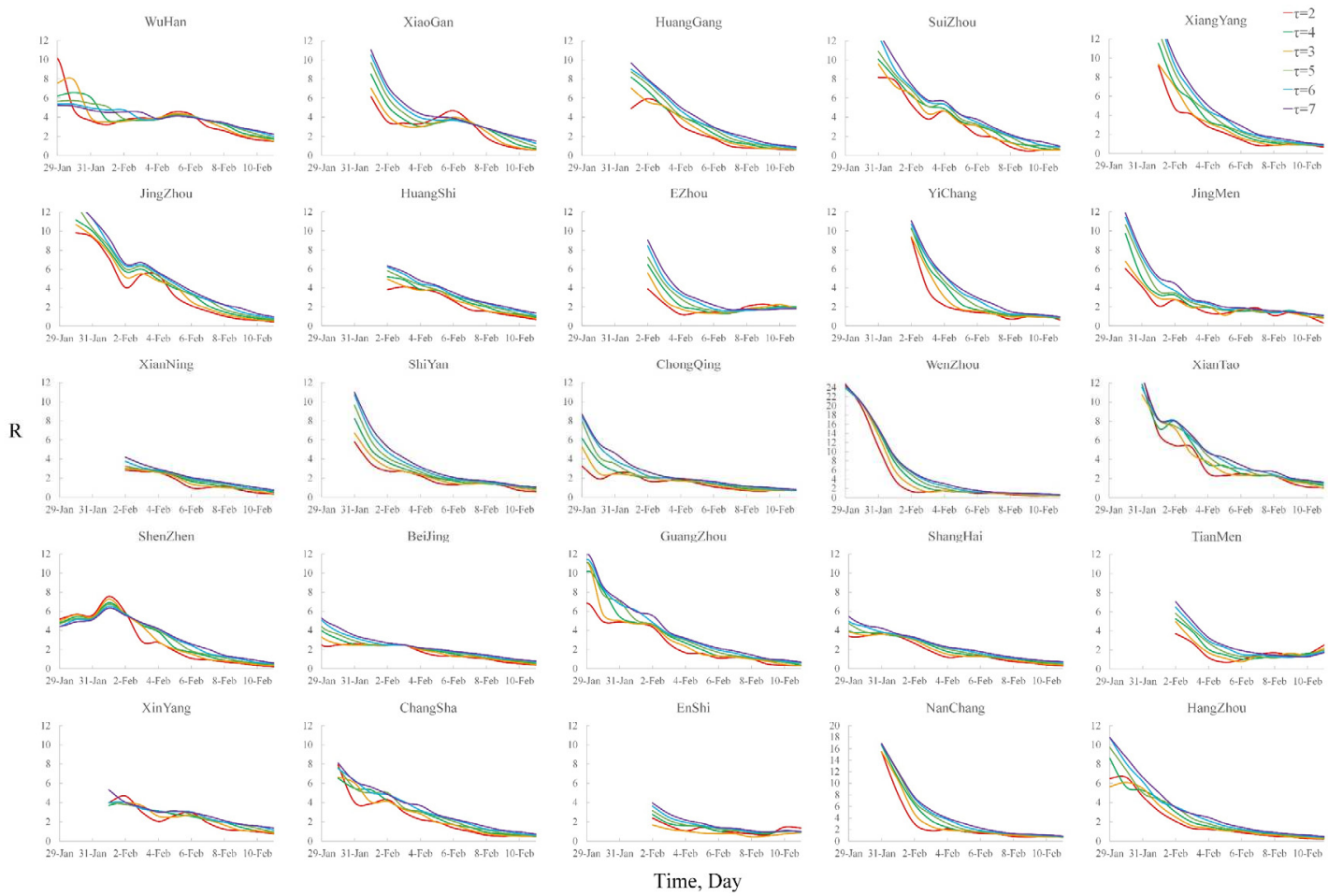

ling Men
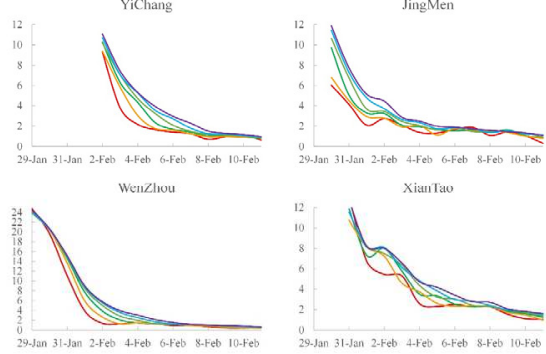

ShangHa
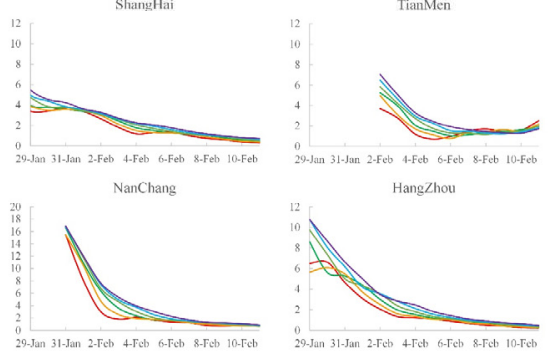

Figure 7: R estimation for 25 cities based on different time windows.

\section{Method and assumption}

\section{Data collection}

In this study, we obtained data on COVID-19 cases in China in 2020 from the Municipal Health Commission of the provinces of the People's Republic of China. The data obtained is publicly available data data, and were aggregated to daily counts.

\section{Time-varying reproduction numbers estimation method}

We model COVID-19 transmission with a Poisson process by assuming the distribution of infectiousness through time after infection is independent of calendar time[6], so that the rate at which someone infected in time step $t-s$ generates new infections in time step $t$, is equal to $R_{\mathrm{t}} w_{\mathrm{s}}$, where $R_{t}$ is the instantaneous reproduction number at time $t$ and $w_{\mathrm{s}}$ a probability distribution describing the average infectiousness profile after infection. The number of infected at time $t$ is a

Poisson distribution with $R_{\mathrm{t}} \sum_{\mathrm{s}=1}^{t} I_{t-s} w_{s}$ as the mean, $I_{t-s}$ is the incidences at time step $t-s$, and the

likelihood of the incidence $I_{t}$ given the reproduction number $R_{\mathrm{t}}$, conditional on the previous incidences $I_{0,}, \ldots, I_{t-1}$, is $[6]$

$$
P\left(I_{t} \mid I_{0}, \ldots, I_{t-1}, w, R_{t}\right)=\frac{\left(R_{t} \Lambda_{t}\right)^{I_{t}} e^{-R_{t} \Lambda_{t}}}{I_{t} !}
$$

Where $\Lambda_{t}=\sum_{s=1}^{t} I_{t-s} w_{s}$. 
If the transmission rate of COVID-19 is a constant within the time window $[t-\tau+1, t]$, which measured by the reproduction number, it is denoted as $R_{t, \tau}$. The likelihood of the incidence during this time period, $I_{t-\tau+1}, \ldots, I_{t}$ given the reproduction number $R_{t, \tau}$, conditional on the previous incidences $I_{0}, \ldots, I_{t-\tau}$, is

$$
P\left(I_{t-\tau+1}, \ldots, I_{t} \mid I_{0}, \ldots, I_{t-\tau}, w, R_{t, \tau}\right)=\prod_{s=t-\tau+1}^{t} \frac{\left(R_{t, \tau} \Lambda_{s}\right)^{I_{s}} e^{-R_{t, \tau} \Lambda_{s}}}{I_{s} !}
$$

A Bayesian method using a Gamma distribution with parameters $(a, b)$ as parameters is used to represent $R_{t, \tau}$, and the posterior distribution $R_{t, \tau}$ is expressed as

$$
\begin{aligned}
P\left(I_{t-\tau+1}, \ldots, I_{t}, R_{t, \tau} \mid I_{0}, \ldots, I_{t-\tau}, w\right) & =P\left(I_{t-\tau+1}, \ldots, I_{t}, R_{t, \tau} \mid I_{0}, \ldots, I_{t-\tau}, w, R_{t, \tau}\right) P\left(R_{t, \tau}\right) \\
& =R_{t, \tau}^{a+\sum_{s=t-\tau+1}^{t} I_{s}-1} e^{-R_{t, \tau}\left(\sum_{s=t-\tau+1}^{t} \Lambda_{s}+\frac{1}{b}\right)} \prod_{s=t-\tau+1}^{t} \frac{\Lambda_{s}}{I_{s} !} \frac{1}{\Gamma(a) b^{a}}
\end{aligned}
$$

So the $R_{t, \tau}$ posterior distribution is a Gamma distribution with $\left(a+\sum_{s=t-\tau+1}^{t} I_{s}, \frac{1}{\frac{1}{b}+\sum_{s=t-\tau+1}^{t} \Lambda_{s}}\right)$ as a parameter. In this paper we use a gamma prior distribution with parameters $a=1$ and $b=5$ to estimate $R_{t, \tau}$.

We used the number of infected per day as the incidences. Therefore, the unknown parameters in the above formula are time window $\tau$ and $w_{\mathrm{s}}$. The estimated value of $R_{\mathrm{t}}$ depends on the choice of the size of the time window $\tau$. Smaller $\tau$ will result in faster detection of COVID-19 transmission changes, but also lead to more statistical noise; Larger $\tau$ will result in smoother and less statistical noise. According to formula (3), the posterior variation coefficient $R_{t, \tau}$ is $1 / \sqrt{a+\sum_{s=t-\tau+1}^{t} I_{s}}$. Assuming that the posterior coefficient of variation must be less than a threshold $\mathrm{CV}$, the minimum number of cases in the time window must satisfy $\sum_{s=t-\tau+1}^{t} I_{s} \geq \frac{1}{C V^{2}}-a$. If $\mathrm{CV}=$ 0.3 [1], the number of outbreaks must be greater than 11 within the time window. According to the number of the infected datasets, the number of infected in a single day in some cities is less than 11, but the number of new infected in 3 days are all greater than 11 .

The infectivity profile $w_{\mathrm{s}}$ can be approximated by the distribution of the serial intervals [6], we assumed that the serial interval distribution had a mean $( \pm \mathrm{SD})$ of $7.5 \pm 3.4$ days $(95 \% \mathrm{CI}, 5.3$ to 19$)$ from the [3]. Actually, [6] showed that the estimates of $\mathrm{R}$ were little sensitive to the choice of the prior mean and variance of serial interval.

In addition, a serial correlation method [7] was used to calculate the correlation of the R time 
series among cities. Specifically, the change in the $\mathrm{R}$ estimation over time is considered to be a time series of R. Let the time series of $\mathrm{R}$ of two cities be $X$ and $Y$ respectively, then the correlation coefficient of $X$ and $Y$ is

$$
\operatorname{corr}(X, Y)=\frac{C(X, Y)}{\sqrt{C(X, X) C(Y, Y)}}
$$

Where $C(X, Y)=\frac{\sum_{i=1}^{n}\left(X_{i}-\bar{X}\right)\left(Y_{i}-\bar{Y}\right)}{n-1}$, and $n$ is the length of the time series. In this paper, The latest time to start calculating for all cities' $\mathrm{R}$ is February 10, 2020, thus, the time series of $\mathrm{R}$ from February 2 to February 10 is used to calculate the correlation, that is, $n=9$ in this paper.

\section{Author Contributions}

Conceived and designed the experments: QC ZL. Analyzed the data: QC ZL. Contributed reagents/materials/analysis tools: GC JH. Wrote the paper: QC ZL GC JH.

\section{Competing Interests}

The authors declare that they have no competing financial interests.

\section{Data availability}

We confirm that the data obtained is publicly available data, and the data is provided in the Supplementary Information file.

\section{Reference}

[1] Joseph $\mathrm{T} \mathrm{Wu}$, Kathy Leung, Gabriel M Leung. Nowcasting and forecasting the potential domestic and international spread of the 2019-nCoV outbreak originating in Wuhan, China: a modelling study. January 31, 2020, https://doi.org/10.1016/S0140-6736(20)30260-9.

[2] Castillo-Chavez C, Feng Z, Huang W. On the computation of R0 and its role on global stability. In: CastilloChavez C, Blower S, van den Driessche P, Kirschner D, Yakubu A, eds. Mathematical approaches for emerging and reemerging infectious diseases: an introduction. New York: Springer, 2002: 229-50.

[3] Qun Li, M. Med., Xuhua Guan, etc. Early Transmission Dynamics in Wuhan, China, of Novel Coronavirus Infected Pneumonia. The NEW ENGLAND JOURNAL of MEDICINE, Jan 29,2020, DOI: 10.1056/NEJMoa2001316.

[4] Jonathan M. Read, Jessica R.E. Bridgen, Derk A.t. Cummins, etc. Novel coronavirus 2019-nCoV: early estimation of epidemiological parameters and epidemic prediction. Jan. 24, 2020: doi:http://dx.doi.org/10.110/2020.01.23.20018549.

[5] Zhou Tao, Liu Quan-Hui, Yang Zimo, etc. Preliminary prediction of the basic reproduction number of the Wuhan novel coronavirus 2019-nCoV.

[6] Anne Cori, Neil M.Ferguson, Christophe Fraser and Simon Cauchemez. A New Framework and Software to Estimate Time-Varying Reproduction Numbers During Epidemics. American Journal of Epidemiology,2013,9(178):1505-1512.

[7] Harvey, A. C. The Econometric Analysis of Time Series. 2nd ed. Cambridge, MA: MIT Press. 1990.

[8] Anderson R, May R. Infectious Diseases of Humans: Dynamics and Control. Oxford, United Kingdom: Oxford 
University Press, 1991.

[9] Wei-jie Guan, Zheng-yi Ni, Yu Hu, Wen-hua Liang, etc. Clinical characteristics of 2019 novel coronavirus infection in China. medRxiv 2020.02.06.20020974, doi: https://doi.org/10.1101/2020.02.06.20020974. 


\begin{tabular}{lrrrrrrrr}
\multicolumn{1}{r}{ CITy } & 11-Jan & 12-Jan & 13-Jan & 14-Jan & 15-Jan & 16-Jan & 17-Jan & 18-Jan \\
\cline { 1 - 3 } & 0 & 0 & 0 & 0 & 0 & 0 & 0 & 0 \\
Shanghai & 0 & 0 & 0 & 0 & 0 & 0 & 0 & 0 \\
Hangzhou & 0 & 0 & 0 & 0 & 0 & 0 & 0 & 0 \\
Wenzhou & 0 & 0 & 0 & 0 & 0 & 0 & 0 & 0 \\
Nanchang & 0 & 0 & 0 & 0 & 0 & 0 & 0 & 0 \\
Xinyang & 0 & 0 & 0 & 0 & 0 & 0 & 0 & 0 \\
Wuhan & 41 & 0 & 0 & 0 & 0 & 4 & 17 & 59 \\
Huangshi & 0 & 0 & 0 & 0 & 0 & 0 & 0 & 0 \\
Shiyan & 0 & 0 & 0 & 0 & 0 & 0 & 0 & 0 \\
Yichang & 0 & 0 & 0 & 0 & 0 & 0 & 0 & 0 \\
Xiangyang & 0 & 0 & 0 & 0 & 0 & 0 & 0 & 0 \\
Ezhou & 0 & 0 & 0 & 0 & 0 & 0 & 0 & 0 \\
Jingmen & 0 & 0 & 0 & 0 & 0 & 0 & 0 & 0 \\
Tianmen & 0 & 0 & 0 & 0 & 0 & 0 & 0 & 0 \\
Xiaogan & 0 & 0 & 0 & 0 & 0 & 0 & 0 & 0 \\
Jingzhou & 0 & 0 & 0 & 0 & 0 & 0 & 0 & 0 \\
Huanggang & 0 & 0 & 0 & 0 & 0 & 0 & 0 & 0 \\
Xianning & 0 & 0 & 0 & 0 & 0 & 0 & 0 & 0 \\
Suizhou & 0 & 0 & 0 & 0 & 0 & 0 & 0 & 0 \\
Xiantao & 0 & 0 & 0 & 0 & 0 & 0 & 0 & 0 \\
Enshi & 0 & 0 & 0 & 0 & 0 & 0 & 0 & 0 \\
Changsha & 0 & 0 & 0 & 0 & 0 & 0 & 0 & 0 \\
Guangzhou & 0 & 0 & 0 & 0 & 0 & 0 & 0 & 0 \\
Shenzheng & 0 & 0 & 0 & 0 & 0 & 0 & 0 & 0 \\
Chongqing & 0 & 0 & 0 & 0 & 0 & 0 & 0 & 0 \\
& & & 0 & & & & &
\end{tabular}




$\begin{array}{rrrrrrrrr}\text { 19-Jan } & 20-\text { Jan } & 21-\text { Jan } & 22-\text { Jan } & 23-\text { Jan } & 24-\text { Jan } & 25-\text { Jan } & 26-\text { Jan } & 27-\text { Jan } \\ 0 & 5 & 5 & 4 & 12 & 10 & 15 & 17 & 12 \\ 0 & 1 & 8 & 7 & 4 & 13 & 7 & 13 & 13 \\ 0 & 0 & 1 & 0 & 5 & 6 & 15 & 0 & 5 \\ 0 & 0 & 2 & 2 & 2 & 4 & 8 & 14 & 28 \\ 0 & 0 & 0 & 1 & 1 & 1 & 1 & 4 & 9 \\ 0 & 0 & 0 & 0 & 1 & 4 & 16 & 1 & 6 \\ 77 & 60 & 107 & 60 & 70 & 77 & 46 & 80 & 892 \\ 0 & 0 & 0 & 0 & 0 & 0 & 31 & 5 & 17 \\ 0 & 0 & 0 & 0 & 1 & 4 & 15 & 20 & 25 \\ 0 & 0 & 0 & 0 & 0 & 0 & 19 & 11 & 20 \\ 0 & 0 & 0 & 0 & 0 & 0 & 2 & 34 & 34 \\ 0 & 0 & 0 & 0 & 0 & 1 & 0 & 19 & 37 \\ 0 & 0 & 0 & 1 & 7 & 13 & 17 & 52 & 24 \\ 0 & 0 & 0 & 0 & 0 & 3 & 2 & 8 & 10 \\ 0 & 0 & 0 & 0 & 0 & 4 & 29 & 45 & 73 \\ 0 & 0 & 0 & 6 & 2 & 2 & 23 & 14 & 24 \\ 0 & 12 & 0 & 0 & 0 & 0 & 58 & 32 & 59 \\ 0 & 0 & 0 & 0 & 0 & 0 & 43 & 21 & 27 \\ 0 & 0 & 0 & 0 & 0 & 5 & 31 & 16 & 18 \\ 0 & 0 & 0 & 0 & 2 & 8 & 1 & 1 & 15 \\ 0 & 0 & 0 & 0 & 0 & 11 & 6 & 8 & 13 \\ 0 & 0 & 1 & 3 & 4 & 0 & 10 & 4 & 2 \\ 0 & 0 & 2 & 3 & 2 & 7 & 0 & 25 & 12 \\ 0 & 9 & 5 & 1 & 0 & 5 & 7 & 9 & 13 \\ 0 & 0 & 5 & 4 & 8 & 30 & 18 & 35 & 22\end{array}$




$\begin{array}{rrrrrrrrr}28-\text { Jan } & 29-\text { Jan } & 30-\text { Jan } & 31 \text {-Jan } & 1 \text {-Feb } & 2 \text {-Feb } & 3 \text {-Feb } & 4 \text {-Feb } & 5 \text {-Feb } \\ 11 & 20 & 21 & 24 & 27 & 32 & 16 & 25 & 21 \\ 14 & 21 & 27 & 25 & 24 & 16 & 15 & 25 & 21 \\ 19 & 18 & 16 & 13 & 12 & 8 & 14 & 9 & 10 \\ 54 & 58 & 55 & 14 & 24 & 26 & 49 & 24 & 32 \\ 8 & 21 & 21 & 16 & 6 & 14 & 18 & 13 & 15 \\ 3 & 10 & 7 & 21 & 18 & 11 & 13 & 26 & 26 \\ 315 & 356 & 378 & 576 & 894 & 1033 & 1242 & 1967 & 1766 \\ 33 & 27 & 55 & 41 & 43 & 82 & 71 & 104 & 57 \\ 23 & 31 & 31 & 27 & 35 & 44 & 35 & 27 & 35 \\ 12 & 54 & 50 & 109 & 77 & 39 & 60 & 44 & 67 \\ 61 & 32 & 123 & 61 & 94 & 107 & 84 & 103 & 52 \\ 27 & 39 & 66 & 38 & 51 & 28 & 26 & 50 & 41 \\ 28 & 49 & 36 & 24 & 78 & 16 & 55 & 22 & 86 \\ 11 & 10 & 23 & 15 & 17 & 16 & 2 & 11 & 10 \\ 101 & 125 & 142 & 87 & 121 & 169 & 202 & 342 & 424 \\ 30 & 50 & 70 & 66 & 46 & 166 & 114 & 100 & 88 \\ 111 & 172 & 77 & 153 & 276 & 244 & 176 & 223 & 162 \\ 21 & 18 & 36 & 40 & 40 & 50 & 52 & 36 & 15 \\ 46 & 27 & 85 & 76 & 80 & 74 & 183 & 65 & 128 \\ 2 & 23 & 35 & 7 & 43 & 29 & 19 & 37 & 40 \\ 13 & 15 & 9 & 12 & 18 & 6 & 12 & 15 & 6 \\ 22 & 11 & 11 & 18 & 26 & 13 & 23 & 16 & 15 \\ 12 & 16 & 27 & 31 & 38 & 14 & 27 & 21 & 18 \\ 14 & 23 & 24 & 60 & 26 & 30 & 43 & 20 & 25 \\ 15 & 18 & 41 & 32 & 24 & 38 & 37 & 29 & 23\end{array}$




$\begin{array}{rrrrr}6-\text { Feb } & 7 \text {-Feb } & 8 \text {-Feb } & 9 \text {-Feb } & 10-\text { Feb } \\ 23 & 18 & 11 & 11 & 5 \\ 15 & 12 & 11 & 3 & 7 \\ 5 & 6 & 3 & 2 & 2 \\ 25 & 17 & 10 & 16 & 10 \\ 13 & 6 & 11 & 11 & 6 \\ 12 & 16 & 13 & 15 & 8 \\ 1501 & 1985 & 1379 & 1921 & 1552 \\ 69 & 68 & 57 & 52 & 30 \\ 42 & 43 & 29 & 14 & 24 \\ 47 & 23 & 78 & 45 & 23 \\ 51 & 69 & 81 & 57 & 44 \\ 48 & 98 & 70 & 89 & 65 \\ 45 & 35 & 75 & 12 & 15 \\ 25 & 16 & 18 & 20 & 44 \\ 255 & 172 & 123 & 105 & 101 \\ 84 & 56 & 56 & 48 & 30 \\ 90 & 144 & 100 & 115 & 80 \\ 44 & 33 & 17 & 14 & 8 \\ 81 & 38 & 31 & 65 & 46 \\ 42 & 52 & 20 & 37 & 22 \\ 13 & 3 & 11 & 21 & 8 \\ 11 & 6 & 9 & 8 & 6 \\ 29 & 14 & 6 & 9 & 4 \\ 20 & 17 & 13 & 4 & 7 \\ 22 & 15 & 20 & 22 & 18\end{array}$




\section{Figures}

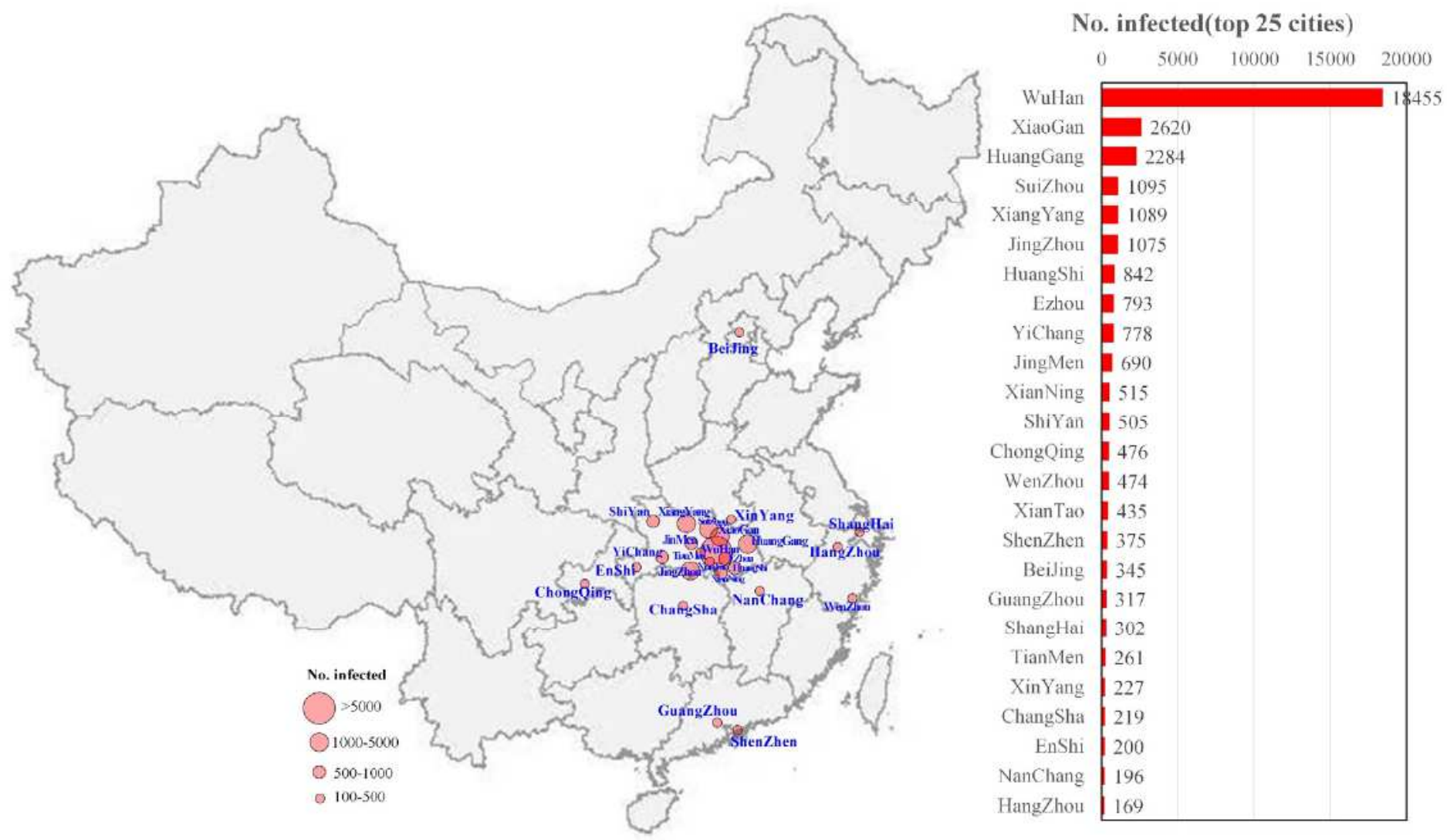

\section{Figure 1}

Spatial distribution of 25 China's worst cities for COVID-19 epidemic. Note: The designations employed and the presentation of the material on this map do not imply the expression of any opinion whatsoever on the part of Research Square concerning the legal status of any country, territory, city or area or of its authorities, or concerning the delimitation of its frontiers or boundaries. This map has been provided by the authors. 

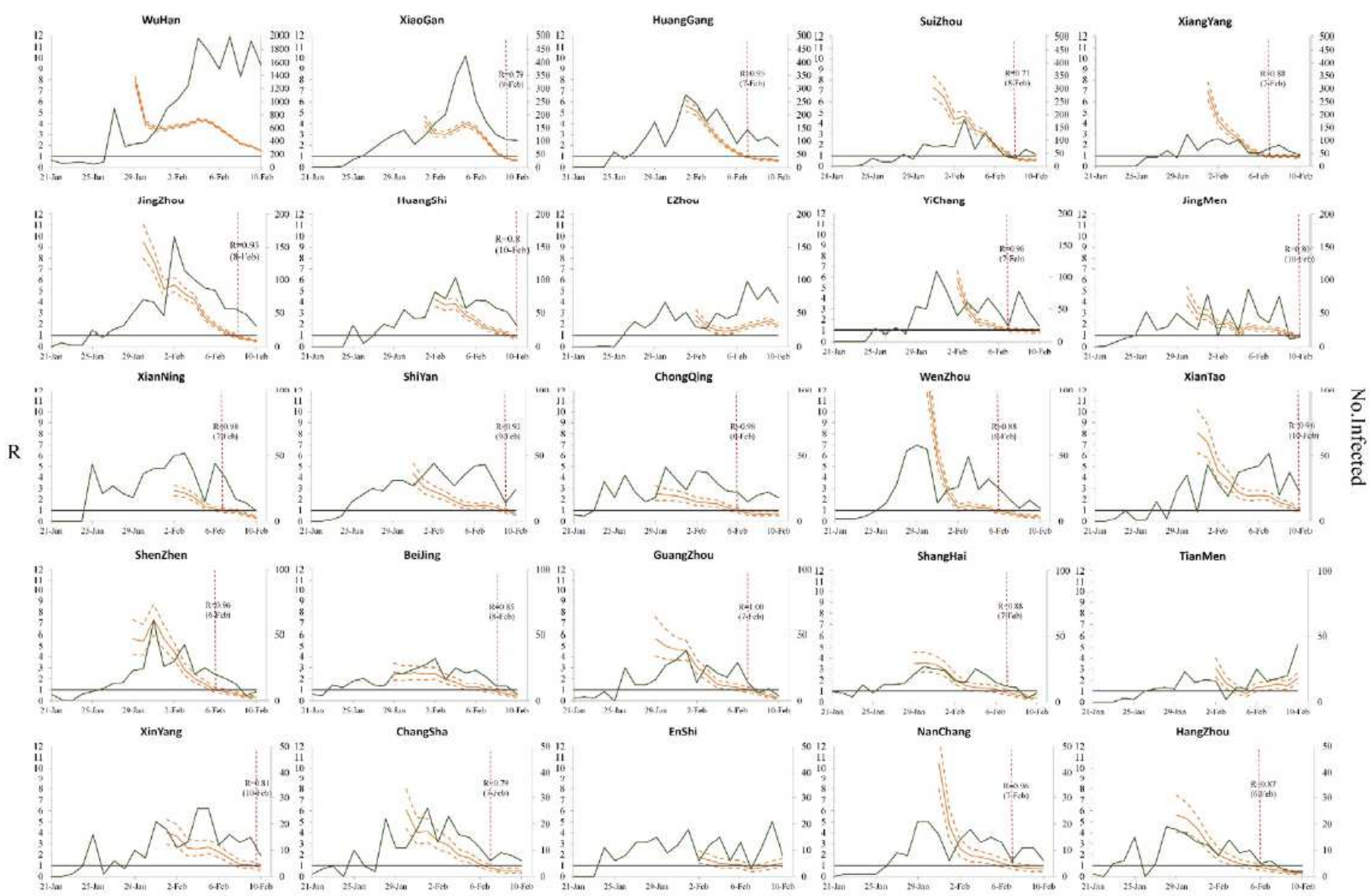

Time, Day

$-\mathrm{R} \quad-\mathrm{R}\left(95^{\circ}\right.$ ocredible interval $) \quad-\mathrm{R}=1 \quad-\mathrm{No}$, infected $\quad, \mathrm{R} 1 \mathrm{1}$ begining time

Figure 2

R change trends of 25 China's worst cities for COVID-19 epidemic.

res

Figure 3

The correlation coefficient of $\mathrm{R}$ time series among cities. 


\begin{tabular}{|c|c|c|c|c|c|c|c|c|c|c|c|c|c|c|c|c|c|c|c|c|c|c|c|c|c|c|}
\hline Ezhou & & 000 & 024 & 034 & 027 & 0.09 & 079 & 065 & 082 & 037 & 038 & 095 & 032 & 0660 & 094 & 042 & 043 & $08 ?$ & 027 & 056 & 0.39 & 0.63 & 055 & 057 . & 052 & \\
\hline TianMen & 0.00 & & 045 & 054 & $0.0 t$ & 0.03 & ors. & 092 & 057 & 023 & 048 & Q64 & 0.16 & 0.40 & 065 & 041 & 028 & 0.53 & 0.14 & 035 & 0.21 & 039 & 030 & 0,32 & 0.29 & \\
\hline XiaoGan & 024 & 0.45 & & $0 \infty 0$ & Q.4a & 031 & 005 & 000 & 000 & 0.7 & 0.12 & 002 & 0.16 & 0.05 & 001 & 006 & 007 & 004 & 0.12 & aca & $0 . a t$ & 002 & 006 & 004 & 004 & \\
\hline Wullan & 034 & 0.54 & 000 & & 0.28 & 0.19 & 0.05 & 0.00 & 0,00 & 003 & 004 & 0,00 & 0,05 & 0.01 & 0,000 & 001 & 0.03 & 0.01 & 0.05 & 0.01 & 0.03 & 0.01 & 0,02 & 0,01 & 0.01 & \\
\hline EnShi & 027 & 0.07 & 048 & 0.28 & & 0.00 & 0.29 & 0.11 & 004 & 003 & 0,00 & 002 & 0.00 & 001 & 0.08 & 002 & 004 & 001 & 001 & 0.03 & 0.02 & 0.03 & 0.01 & 001 & 0.01 & \\
\hline YiChang & 009 & 003 & 0.31 & 0.19 & 0.00 & & 006 & 0.07 & 001 & 000 & 000 & and & 0.00 & 0.00 & 001 & $D C 0$ & 0.00 & 0.01 & 000 & 0.00 & 0.00 & 090 & $0, \infty$ & $0 \infty 0$ & 0.00 & \\
\hline JingMen & 079 & 073 & 005 & 0.05 & 0.29 & 0.06 & & 001 & 002 & 0.01 & 0.04 & $a \infty 2$ & 0.06 & 005 & 005 & 003 & 001 & 007 & 0.03 & 0.02 & 001 & 001 & 002 & 003 & 001 & \\
\hline Wen/hou & 065 & 092 & 000 & 000 & 0.11 & dor & 001 & & 000 & 001 & aor & 000 & oat & 0.00 & 000 & 000 & 0,00 & 000 & oot & 000 & 000 & 0.00 & 000 & 000 & 000 & \\
\hline XinYang & 082 & 057 & 000 & 000 & 004 & oos & 002 & 000 & & 000 & 000 & 000 & 0.00 & 0.00 & 0.00 & 000 & 000 & 000 & 000 & 000 & 0.00 & 0.00 & 000 & 000 & 000 & \\
\hline XianTao & 037 & 0.23 & 007 & 003 & 0.03 & 0.00 & 0.01 & 0.01 & 0.00 & & 000 & 000 & 0.00 & 0.00 & 000 & 000 & 000 & 000 & 000 & 0.00 & 0.00 & 0.00 & 0,00 & 000 & 0.00 & \\
\hline FuangGang & 036 & 018 & 012 & 004 & 000 & 0.00 & 004 & 001 & 000 & 000 & & 200 & 000 & 0.00 & 000 & 000 & $B D O$ & 000 & $Q D O$ & 000 & 0.00 & 000 & $\infty \infty$ & 000 & 0.00 & \\
\hline Sui/hou & 095 & 064 & 002 & 000 & 0.02 & Dot & 0.02 & 0.00 & 000 & 000 & 000 & & 0.00 & 0.00 & 0,00 & 000 & 0.00 & 0.00 & 000 & 0.00 & 0.00 & 000 & 000 & 000 & 0.00 & \\
\hline Xiang Yang & 032 & 016 & 0.16 & 005 & 0,00 & 000 & 0.06 & 001 & 000 & 000 & 000 & 000 & & 0.00 & 000 & 000 & 000 & 000 & 000 & 000 & 0.00 & 000 & $0 \infty$ & 000 & 0.00 & \\
\hline Jing7hou & 066 & 040 & aus & 001 & 0.01. & 0.00 & 005 & 000 & 000 & 000 & 000 & 000 & 0.00 & & 000 & 000 & 000 & 000 & 000 & 000 & 0.00 & 000 & 0.00 & 000 & 0.00 & \\
\hline HuangShi & 094 & 0.65 & 001 & 0.00 & 0.09 & 0.01 & 0.05 & 000 & 000 & 000 & 000 & 000 & 0.00 & 0.00 & & 000 & 000 & 000 & 0.00 & 0.00 & 0.00 & 0.00 & 000 & 0,00 & 0.00 & \\
\hline XianNing & 0.52 & 0.41 & 006 & 001 & 0.02 & 0.00 & 008 & 000 & 000 & 000 & 000 & $0 \infty 0$ & 000 & 000 & 000 & & 000 & 0.00 & 000 & 000 & 000 & 0.00 & $0 \infty$ & 000 & 0.00 & \\
\hline ShiYan & 0,43 & 0.28 & 007 & 000 & 0.04 & 000 & 001 & 000 & 000 & 000 & 000 & 000 & 000 & 000 & 000 & 000 & & 000 & 000 & 900 & 000 & 0.00 & $0 \infty 0$ & 000 & 0,00 & \\
\hline ChongQing & 087 & 0.53 & 004 & 001 & 0.01 & 0.01 & 0.07 & 000 & 000 & 000 & 000 & 900 & 0.00 & 0.00 & $0 \infty 0$ & 000 & 0.00 & & 000 & 0.00 & 0.00 & 0.00 & 000 & 000 & 000 & \\
\hline Shen7hen & 027 & 014 & 012 & 005 & 001 & 0.00 & 003. & 001 & 000 & 000 & $0 \propto 0$ & 000 & 0.00 & 000 & 000 & 000 & 000 & 000 & & 000 & 0.00 & 000 & 000 & 000 & 000 & \\
\hline BeiJing & 0.56 & 0.35 & 0,03 & 001 & o.pa & 0.00 & 002 & 000 & 0.00 & 000 & 000 & 000 & 0.00 & 0.00 & 0.00 & 000 & 000 & 000 & 0.00 & & 000 & 000 & $0 \infty$ & $0, \infty$ & 0,00 & \\
\hline Juang Zhou & 039 & 021 & 007 & 0.03 & 0.02 & 0.00 & 0.01 & 000 & 0.00 & 000 & 000 & 000 & 0,00 & 0.00 & 0.00 & 000 & 0.00 & 000 & 0.00 & 0.00 & & 0.00 & 0,00 & 000 & 0.00 & \\
\hline ShangHai & 063 & 038 & 002 & 0,01 & acas & 0.00 & 001 & 000 & 000 & 000 & $0 \infty$ & $a \infty$ & 000 & 000 & 000 & 000 & 000 & 000 & 000 & 0.00 & 000 & & 000 & 000 & 000 & $p>0.05$ \\
\hline ChangSha & 055 & 0.30 & 006 & 0.02 & 0,01 & 0.00 & 0.02 & 0.00 & 000 & 0.00 & 0.00 & 0,00 & 0.00 & 0.00 & 0.00 & 000 & 0.00 & 0.00 & 000 & 0.90 & 0.00 & 0.00 & & 000 & 0,00 & \\
\hline NanChang & 057 & 032 & 004 & 0.01 & 0.01 & 0.00 & 0.09 & 000 & 000 & 000 & 000 & 000 & .000 & 000 & 000 & 000 & 000 & 000 & 000 & 000 & 0.00 & 000 & 000 & & 000 & $p<0.05$ \\
\hline Hang7hou & 0,2 & 029 & 004 & 001 & 001 & 600 & 0.01 & 0,00 & 000 & 000 & 000 & 000 & 000 & 000 & 0,0 & 000 & 000 & 000 & 000 & 000 & 000 & 000 & 000 & 000 & & \\
\hline & 곯 & 豆 & 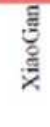 & $\stackrel{\text { E }}{\equiv}$ & 를 & E & $\sum_{\underline{E}}^{5}$ & 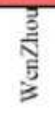 & 兽 & 嚼 & 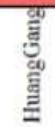 & ปั & 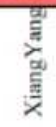 & है & 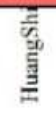 & 产 & 产 & $\begin{array}{l}\text { हू } \\
\text { है } \\
\text { है } \\
\text { है }\end{array}$ & $\begin{array}{l}\text { हू } \\
\text { हू } \\
\text { फै }\end{array}$ & 总 & $\begin{array}{l}\overline{\overline{5}} \\
\frac{5}{5} \\
\frac{\mathrm{E}}{5} \\
\bar{E}\end{array}$ & $\frac{\text { 可 }}{\text { 竞 }}$ & 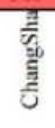 & 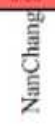 & 旁 & \\
\hline
\end{tabular}

Figure 4

The $p$ value of correlation coefficient of $R$ time series among cities (if the $p<0.05$, the correlation is significant). 


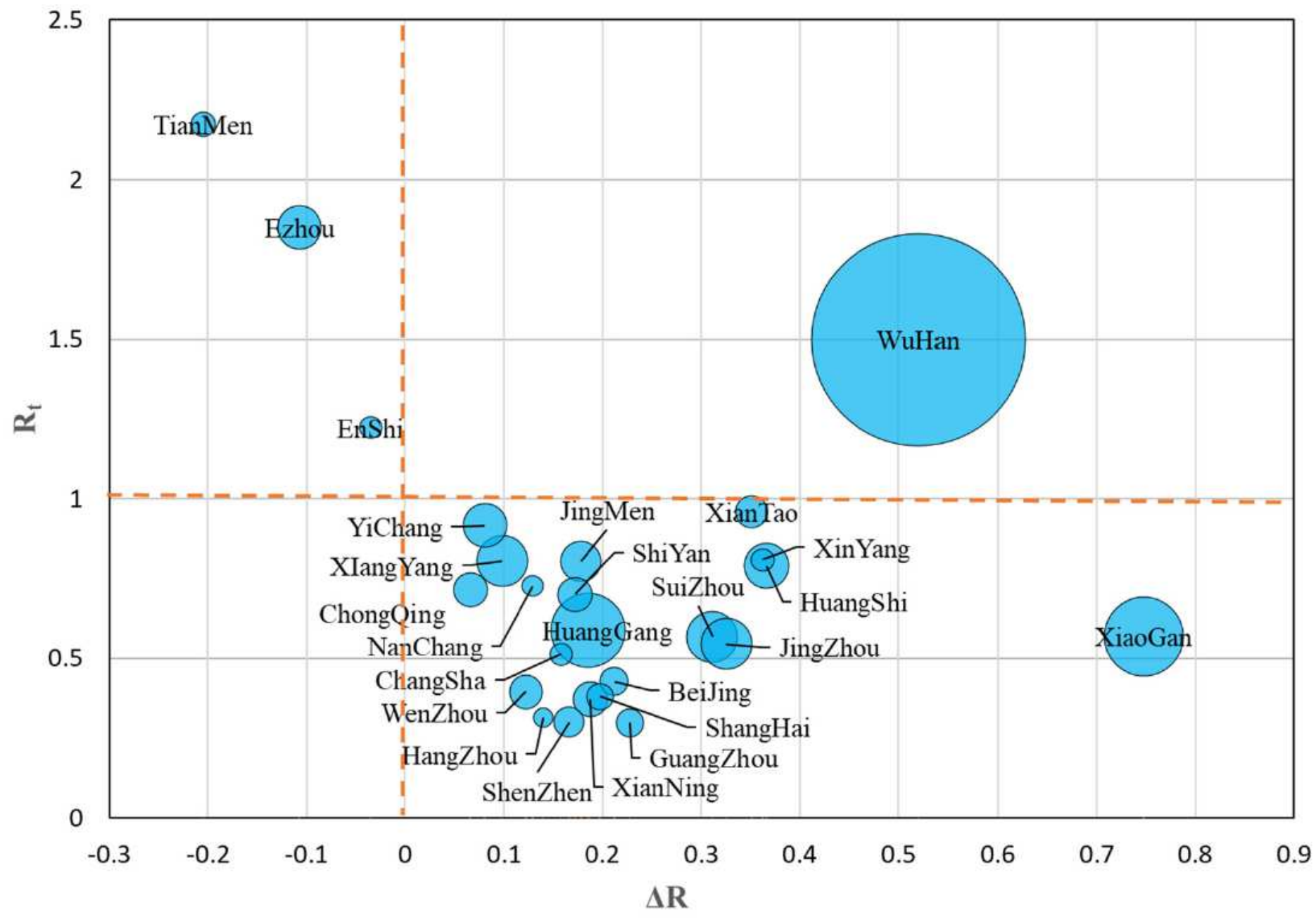

Figure 5

The relationship between the $\mathrm{R}$ value on February 10, 2020 (Rt) and the average decline of $\mathrm{R}$ in the past five days $(\Delta R)$, where the size of the circle represents the number of infected in each city. 


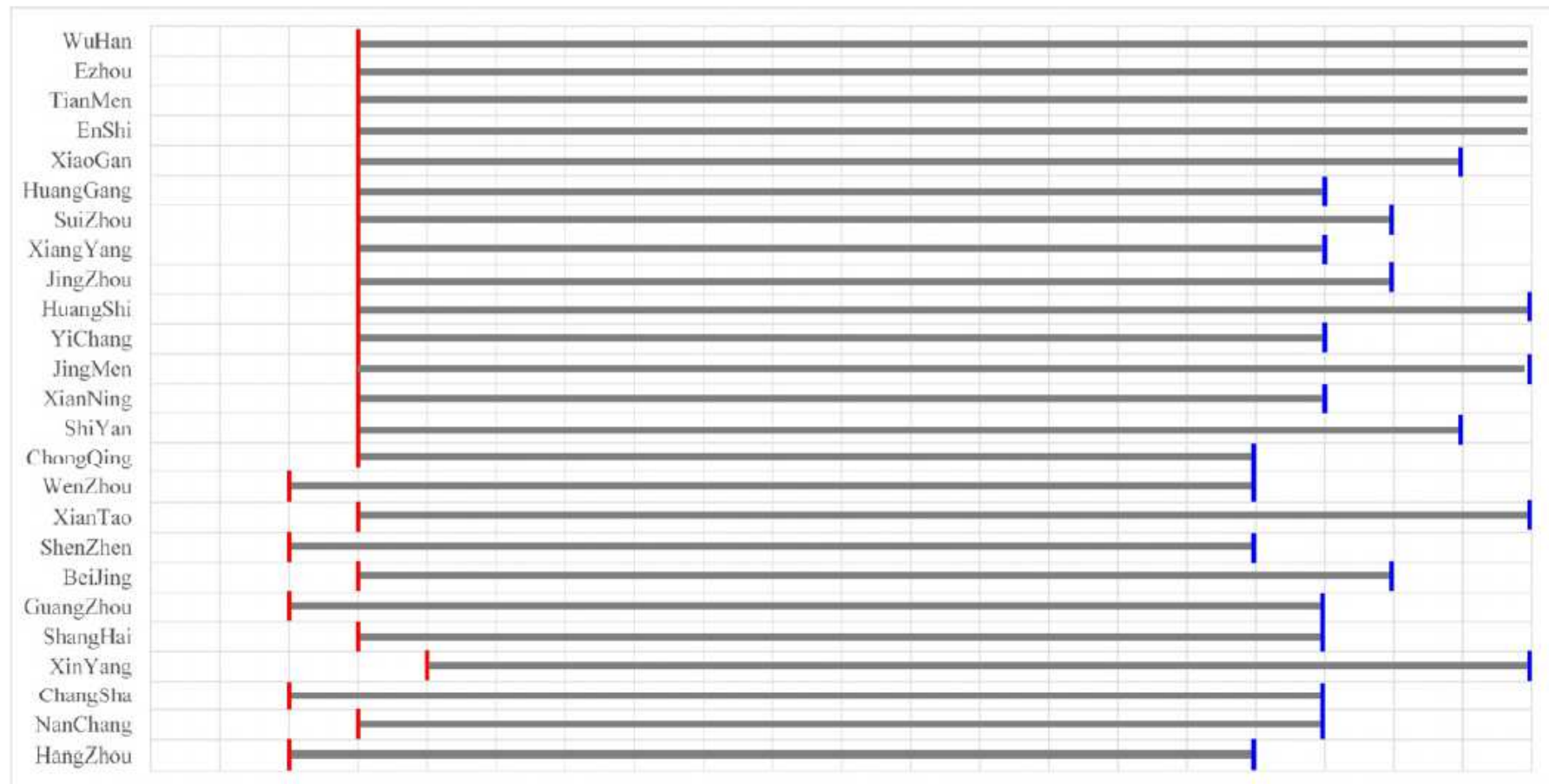

21-Jan 22-Jan 23-Jan 24-Jan 25-Jan 26-Jan 27-Jan 28-Jan 29-Jan 30-Jan 31-Jan 1-Feb 2-Feb 3-Feb 4-Feb 5-Feb 6-Feb 7-Feb 8-Feb 9-Feb 10-Feb

Time, Day

| Start time to initiate first-level public health emergency response

| $\quad R<1$ beginning time

\section{Figure 6}

The time for each city to initiate a first-level public health emergency response and the start time for $\mathrm{R}<1$. 

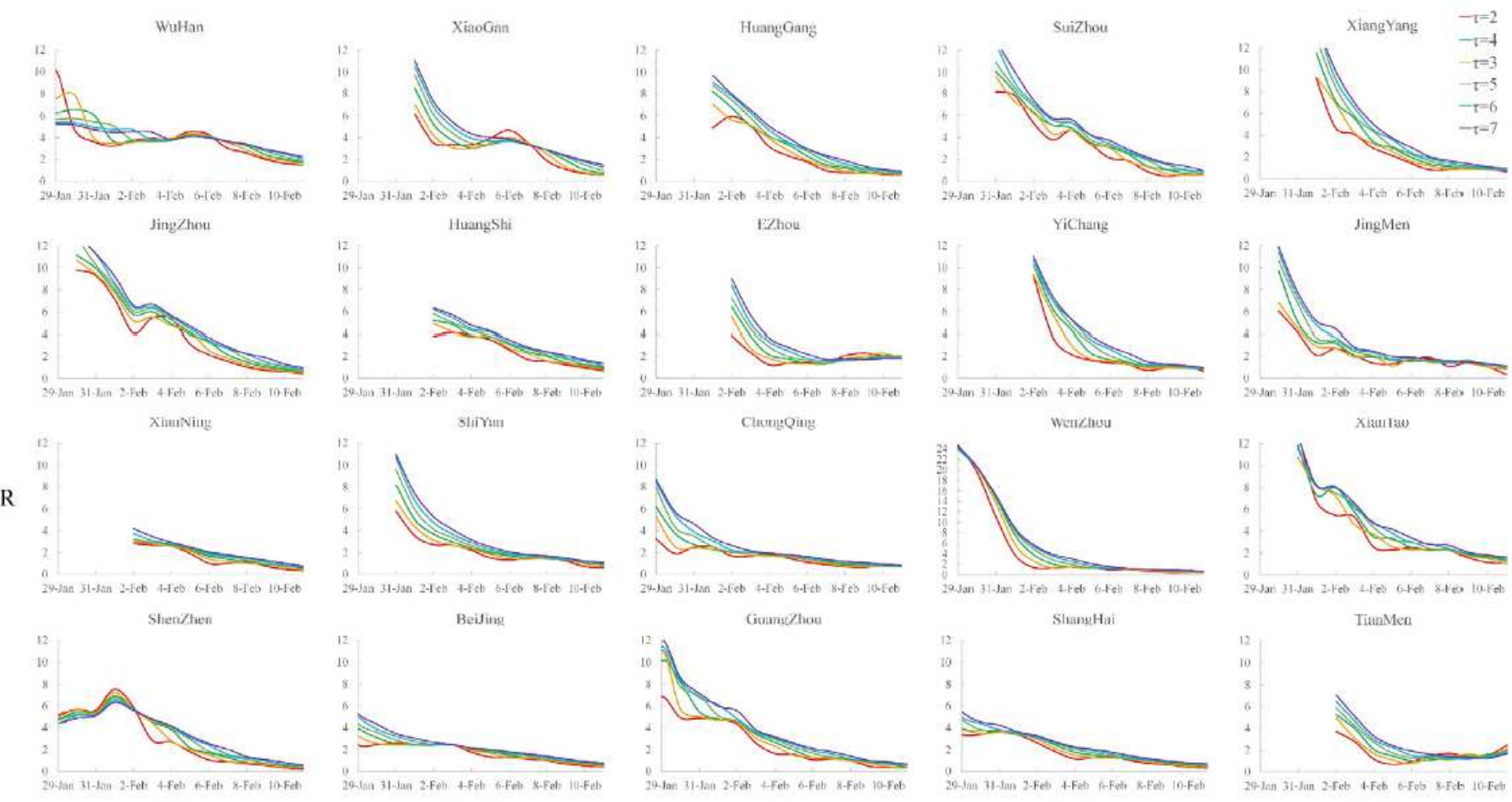

Guany/hou

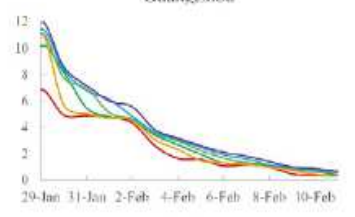

ShangHai
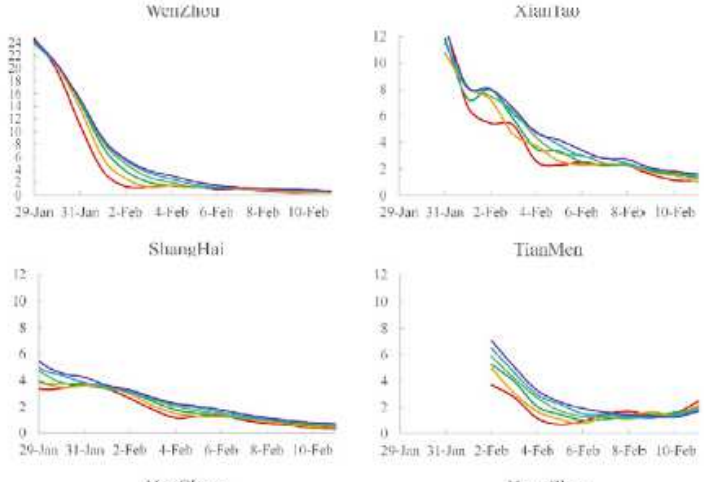

ChangSha

EnShi
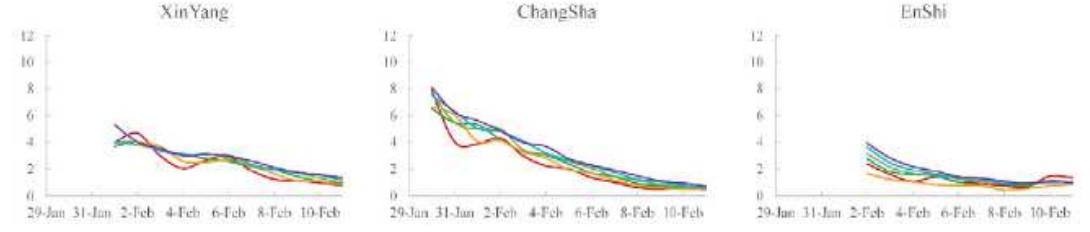

Time, Day
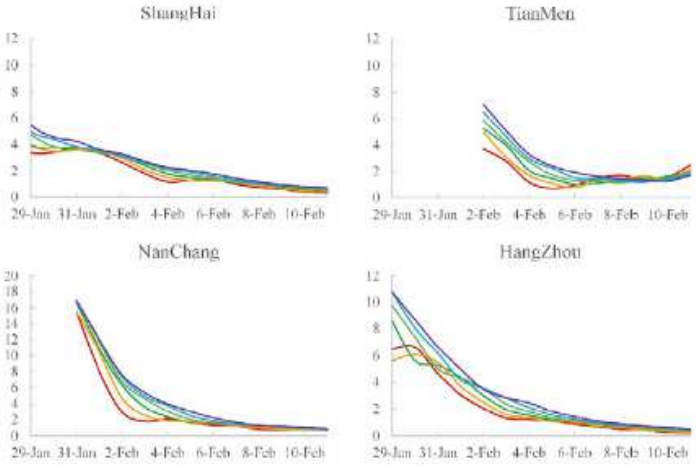

Figure 7

R estimation for 25 cities based on different time windows. 